\title{
PUSH AND PULL FACTORS OF INTERNATIONAL HIGHER EDUCATION: A CASE STUDY OF PAKISTANI FEMALE STUDENTS STUDYING IN MALAYSIA
}

Dr Syed Faisal Hyder Shah*

Musharaf A. Talpur ${ }^{+}$

Dr Abdul Razaque Channa

\begin{abstract}
This paper investigates and analyses various push and pull factors affecting Pakistani female doctoral students to pursue international higher education in Malaysia. The study implemented an open-ended interview approach to collect qualitative data and analysed it using a constant comparative analysis originally developed from Grounded Theory (GT) methodology. The study findings discovered affordability as a major push factor besides other relevant but not less important push factors, such as scholarship conditions to choose Malaysia as a country of destination because of its affordable tuition fees and living expenses. In contrast, this study also identified the principal pull factor that makes Malaysia as a preferred Muslim country for Pakistani women seeking higher education. Other general pull factors, including cultural diversity, lifestyle, security of women and freedom of women, were also found as significantly important as the remaining individual pull factors, such as personal comparison made between Pakistani and Malaysian higher education, students' previous international experience and family bond. Based on these findings, some lessons are learned and discussed in the details for internationalizing our higher education system in Pakistan in the future.
\end{abstract}

Keywords: Female doctoral students, International higher education, Push factors, Pull factors, Affordability

\footnotetext{
* Assistant Professor, Department of Social Work, University of Sindh. Jamshoro, Pakistan. Email: faisal.shah@usindh.edu.pk (Corresponding Author)

${ }^{+}$Assistant Professor, Abida Taherani Sindh Development Studies Centre, University of Sindh, Jamshoro, Pakistan. Email: musharaf.talpur@usindh.edu.pk $\ddagger$ Assistant Professor, Department of Anthropology and Archaeology, University of Sindh, Jamshoro, Pakistan. Email: razaque.channa@usindh.edu.pk
} 


\section{Introduction}

Mobility of international students for the purpose of obtaining higher education is explicitly observed to be driven by its economic benefits like employment, income and social status besides other essential factors, such as striving for international exposure, broadening of knowledge, learning about cultural diversity, acquiring language skills, and above all ornamenting your curriculum-vitae with an international degree (Altbach \& Knight, 2007). Increasing mobility among students is one of the most prominent phenomena of having access to modern higher education throughout the world. Evidently, Pakistan is not among the isolated cases in this arena since the trend for international mobility among the students seeking higher education abroad has been on a rise over the last few decades. For instance, the number of Pakistani international students has extensively increased since the establishment of the Higher Education Commission (HEC) of Pakistan in 2002; however, the overall literacy situation within Pakistan is not very promising from a gender perspective.

According to the Government of Pakistan (2019), the overall literacy rate is 62.3 percent in the country while the female literacy rate is 51.8 percent as compared to 72.5 percent of their male counterparts, whereas only 2.5 percent of female students are enrolled in the higher (or tertiary) education system. Although the number has been significantly increasing over the last few decades, however, the quality of higher education is still a matter of huge concern for many aspiring students in Pakistan. As a result, the demand for quality higher education has expanded, which subsequently compelled many ambitious students in Pakistan, to seek education opportunities abroad. Unfortunately, this important issue concerning the significance of higher education in the sustainable development of Pakistan, specifically the creation of female human capital for the country's growing knowledge-based economy, has been overlooked in the previous research literature. 
With an aim to conduct research on identifying and analyzing factors influencing Pakistani female students' decision to select Malaysia as a country of destination for their higher education, our study has conducted qualitative research based on semi-structured interviews using Grounded Theory (GT) methodology (Glaser \& Struass, 1967; Creswell, 2014; Syed, Talpur \& Shaikh, 2018). Malaysia being an Islamic country with the higher middle-income economy turns out to be a country of destination for Pakistani women Ph.D. students seeking quality higher education (Haider, 2008). More specifically, this research study also found various other appealing factors, such as education affordability as the leading pull factor, and cultural diversity, lifestyle, security of women and freedom for women as the general pull factors overall affecting Pakistani women's access to their international higher education, whereas students' individual international experience, personal comparison made between Pakistani and Malaysian higher education, and family bond were identified as the individual pull-factors affecting Pakistani women students more directly. The subsequent sections of this paper include literature review, methodology, study findings, and conclusions with lessons learned.

\section{Literature Review}

The motives for students to pursue their studies abroad encompass an opportunity to explore a different culture, discover new ways of thinking, making new friends, and enhancing their cross-cultural knowledge and skills (Andrade, 2006). Mainly, students access to international higher education is driven by the economic benefits of their international degree, however, various other factors, such as knowledge attainment, cultural diversity, and enrichment of the curriculum with global substance are also equally relevant (Altbach \& Knight, 2007; Altbach, 2004, Knight, 2006). Due to these factors, international students are recognized as a distinct group of individuals, who are most often mentioned in the literature as an 
entity, rather than individuals with their personal previous international experiences (Koehne, 2005).

Importantly, higher education has now become one of the basic needs for every society and economy, specifically the development of a country that has mainly turned out to be principally dependent on the quality of its higher education (Haider, 2008). The quality higher education and better education system enhance the potential of socioeconomic and cultural development as well as improves the scientific and technological advancements necessary for the knowledge-based economy of a country (Haider, 2008; Batool, Sajid \& Shaheen, 2013). According to Murtaza (2012), this trend of economic competition among the developed and developing countries has resultantly escalated the demand for quality higher education across the globe and compelled aspiring students to avail education opportunities internationally.

Having recognized the role and importance of higher education in the development of a country, increasing students' mobility from their native country to foreign countries across the world has become one of the most prominent phenomena of higher education in the modern days (Chan, 2012; Batool et al., 2013). This trend toward educational mobility has been increasing among Pakistani students over the past few decades. The number of Pakistani international students has remarkably increased since establishment of the Higher Education Commission of Pakistan (HEC) in 2002 (Batool, et al., 2013), however, there is no gender-disaggregated data available to find out the number of Pakistani female students pursuing higher education abroad (Batool et al., 2013). With merely 2.5 percent of female students out of 51.8 percent of overall female literacy rate pursuing their higher education (Government of Pakistan, 2018), women's enrolment in higher education in Pakistan is limited as compared to men. Keeping in view this situation, one can figure out that the number of Pakistani female students who are studying abroad would be far too less (Malik \& Courtney, 2011). 
At primary education level, there are a number of factors, such as the limited number of girls' schools, the unavailability of female teachers, poverty, cultural and family constraints, and the lack of political will and commitment to education, influencing girls' access to the higher education (Khalid \& Mujahid-Mukhtar, 2002), which eventually lead to women's low enrolment in the higher education system of Pakistan and adversely affect the proportion of women in human resource supply in our country (Murtaza, 2012). According to Kazmi (2005), inadequate physical infrastructure, lack of facilities, lack of qualified teachers, out-dated curricula, poor governance, transparency, and limited funds for education, are the key factors behind poor education system that ultimately and critically affect human development in the country.

According to the OECD (2013) report, the number of Pakistani students (both females and males) pursuing higher education abroad was 49,000 during the year 2011, which ranks our country 18 among the top 37 countries of origin of students studying higher education abroad, whereas China stands the first with 723,000 students and India the second with 223,000 students seeking higher education internationally. Bohm et al. (2004) in their comprehensive study on the forecasts of international students entering the United Kingdom (UK) with the purpose of higher education have revealed that Pakistani students have $14 \%$ annual growth in the UK making Pakistan among the top ten countries by 2020 pertaining to international student's mobility in the UK. However, in the wake of September 11, 2001, the number of students from Asian Muslim countries to the USA and Canada, mainly including Saudi Arabia, Kuwait, and Pakistan, has substantially declined (Sirat, 2008). The change in the admission process itself has contributed to the decrease in new enrollments in Western countries.

According to Sirat (2008), Asian students because of confronting several obstacles after 9/11, such as religious and ethnic threats specifically in the Western world coupled with high mobility cost and 
living expenses had no other option left other than to study within their regional countries, including predominantly China, Malaysia and Singapore. Above all, the investments made by the Malaysian governments in higher education during the same time period replaced this country as an emerging destination for students from other Asian countries, including Pakistan (Chan, 2012). As the competition for higher education escalated worldwide, Malaysia like many Asian countries adopted a wide range of similar strategies like Western countries to facilitate international students' mobility, which eventually become a trend of regional (or horizontal) mobility of students within the region of Asian countries (Chan, 2012; Sirat, 2008).

Briers, Shinn, \& Nguyen (2010) have explored the reasons behind motivation among ambitious international students. The reasons delineated by the study include gaining life experience, having an opportunity to live in a different country and culture, increasing employability, adding a foreign in the resume, multiplying personal development, having academic specialization, enhancing work opportunities in different countries and learning another language. Oleksiyenko, Cheng, \& Yip (2013) in their case study of Hong Kong students found that the motivation to study abroad among local students was based on the hope for a better future, learning, and higher independence. Describing the influence of push and pull factors, Li and Bray (2007) described that most of the students are pushed by their families to get international degrees whilst others are pulled by opportunities such as scholarships and other funding possibilities, like reduced tuition fees, travelling grants, studentships and many others. The motivation behind this internationalization is principal because of gaining economic benefits and enhancing and maintaining social status in addition to having other associated academic, social, and cultural benefits (e.g. see Mazzarol \& Soutar, 2001).

Other factors affecting women's access to international higher education may include lifestyle, cultural diversity, the security of 
women and freedom for women. According to Sherry, Thomas \& Chui (2010), international students on their personal levels develop new outlooks, increase their confidence and self-esteem, and tend to increase their level of maturity as a result of their independent life experiences pertaining to many factors, such as their security, freedom, and lifestyle, in another country specifically with a diverse culture.

\section{Methodology}

This research study employed a qualitative research approach for data collection and analysis. Using grounded theory (GT) research methods of data collection and analysis, previously used by Strauss \& Corbin (1990, 98), Creswell (2014), and Syed, et al. (2018) in their studies, based on a series of semi-structured face-to-face interviews with 30 post-graduate Pakistani female students $(\mathrm{N}=30)$ studying in the four public universities located in the Western part of Malaysia. The data was collected using written interview guidelines and an open-ended questionnaire that allowed us for detailed discussions with the respondents to explore specified issues. Besides, the data was audio recorded using a voice recorder and also supplemented by the memos and field notes taken by the researcher.

After qualitative research survey implementation, the data were analysed in a three-step sequential process of coding, namely open, axial and selective coding, and analysis using systematic grounded theory method primarily introduced by two sociologists Glaser \& Struass (1967), and later a detailed work explained by Strauss \& Corbin (1990; 98), and more recently by Creswell (2014). Using the above coding procedure, the categories were developed, resemblances and diversities in the data were sub-categorised, and finally interconnecting the information categories in order to explain the situation. Putting differently, the data was persistently compared using constant comparative method initially presented by Glaser \& Strauss (1967) with an aim of analysing similarities and differences 
that emerged in the responses, and encompassing the relevant incidents and examples to identify the key ideas (Glaser, 1992; 98). Using NVIVO-11 Pro Software (NVIVO, 2018), we performed the above qualitative research analysis of open-ended responses (Syed et al., 2018).

\section{Study Findings 1: Push Factors}

\section{Affordability}

Affordability is one of the main push factors for the study respondent's decision of choosing Malaysia as the destination for their higher studies. Most of the Pakistani women postgraduate students studying in Malaysian public universities are supported by either direct or indirect funding from the HEC, Pakistan. These students have said that they were given clear instruction by their funding agency, i.e. the HEC, Pakistan, to apply in the countries, such as Malaysia, China, and Thailand, where there are no or even fewer tuition fees. The respondents further explained that the limited amount they were awarded they could barely afford to live in Malaysia. Out of thirty study respondents, 08 respondents were sponsored by the HEC, Pakistan, 03 respondents were partially sponsored by the public sector universities in the country, whereas the remaining were on self-finance.

Obviously, affordability was found as the main push factor behind those respondents' decisions to seek higher education in Malaysia. Most of the respondents were planning to go to Europe and Australia, but they came to Malaysia due to their financial constraints. Out of 30 female respondents, 15 respondents were doing their doctoral studies in Malaysia on self-finance, 08 Students were on (HEC) funded scholarship and 07 were financially supported by their parents.

The three female students doing Ph.D. degree on self-finance, one with her doctoral degree monetarily supported by her parents, and one awarded with the HEC funded foreign scholarship were of the 
unanimous opinion that the affordability was the main reason before they came to study in Malaysia. Although initially, they planned to go to Europe or even Australia, they chose Malaysian public universities because of high fees structures and unaffordable living expenses in those Western countries. These views exhibit that affordability, by and large, is the main concern specifically among the female doctoral students on self-finance. Figure 1 represents the verbal accounts of the female doctoral respondents on affordability. A female enrolled in the second year of her Ph.D. studies in a Malaysian public university on self-finance narrated that further supported the above notion:

Malaysia was the best destination for me as other countries were not within my means. I concluded that Malaysia is the only country which has the average living cost with affordable tuition fees and good standards of education.

Figure 1: The verbal accounts of the respondents on affordability.

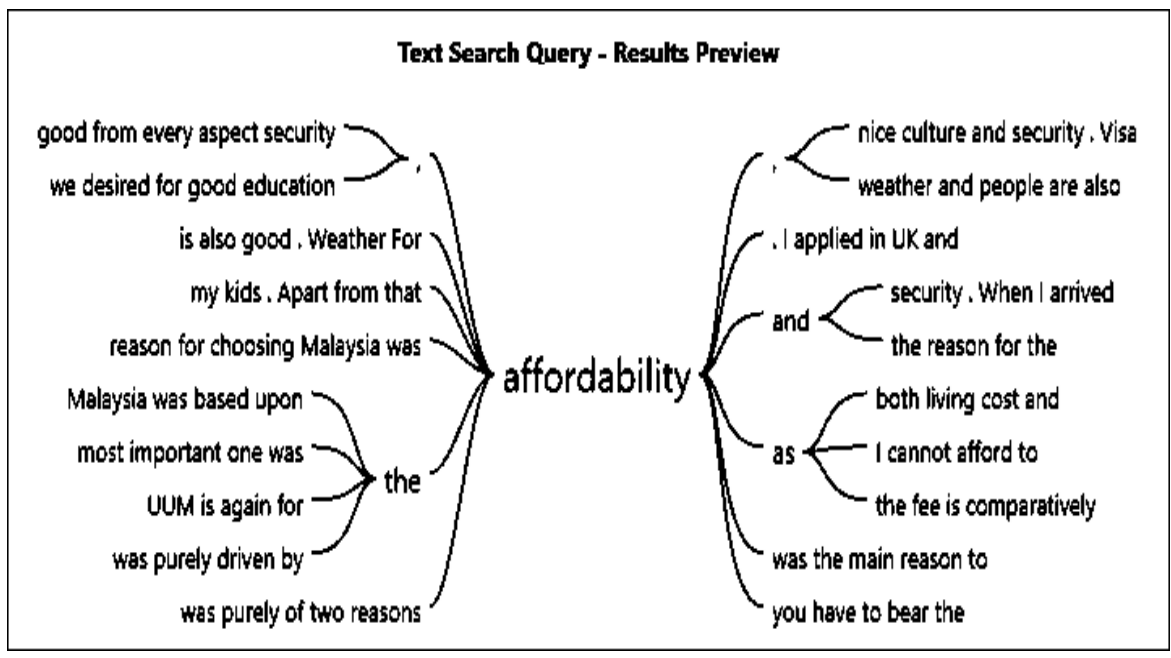




\section{Findings 2: Pull Factors}

\section{Islamic state}

The decision to select Malaysia as a destination country was solely made by most of the respondents; however, the same decision was not exclusively respondents' own decision in all cases because, for instance, some students made the decision alike after having a mutual agreement between them and their parents. When we asked a question from the respondents how they found Malaysia as an Islamic state? The respondents, on the whole, answered that their parents were delighted to send them in a peaceful and progressive Islamic country, and Malaysia always stood their parents' top priority. When we asked the respondents about the main reason behind this mutual decision, they answered that their parents were not feeling happy to allow their daughters to study in any non-Islamic country because of seeing them as women, so it was mandatory for them to choose an Islamic country with almost similar religious society. The respondents also shared their hard times they confronted in convincing their parents because of knowing that most of the Pakistani parents do not even allow their daughters to study outside their home towns even within the same province of the country. A married Pakistani female doctoral student living with her family and studying in the second year of her Ph.D. studies informed:

She always wanted to do a Ph.D. from abroad on self-finance, but the first thing their parents asked her was to do a Ph.D. from any Muslim country with a quality higher education and security of women.

Similarly, another female doctoral student in her second year of the doctoral programme and who was awarded the HEC scholarship affirmed her head of the department encouraged her to pursue higher studies in Malaysia. She shared that her teacher and senior fellows mentioned that Malaysia is a Muslim country with a good environment for women. Knowing this, her family was also happy 
that she was coming to Malaysia as they knew that Malaysia is an Islamic country and internationally acknowledged so far as women's security is concerned. A female Ph.D. student living with her family and studying in the second year of her studies commented:

Only after coming to Malaysia, she realized that it is more like an Islamic country than she was heard about. She thought that it would be a secular Islamic state as its substantial number of population is non-Muslim. For her, it is good in the sense that she was living with her kids and they can see and learn from this country's good Islamic environment that offers a good standard of living, better higher education facilities and a great sense of security of women.

\section{Cultural diversity}

Malaysian culture has a full diversity in terms of its different kinds of religions, races, and ethnicities, so this has become one of the appealing pull factors for Pakistani women students selecting Malaysia as their destination for higher studies. The respondents shared that they did not only enjoy being here, but they also learned many other important aspects, such as respect for other religions and ethnicities. Furthermore, the respondents also mentioned that the local culture is adaptive as it offers friendly surroundings. A female doctoral student studying in the fourth year affirmed:

Even though Malaysia is a Muslim state, I observed some positive things in terms of religious harmony instead of having so many other religions over here. I really found so much understanding among all religions as they all live in peace and unity, and they exercise their religious practices freely. What surprised me most is that there are so many religious holidays in Malaysia like Diwali, Christmas, and Chinese New Year in addition to its main Muslim religious holidays. 
According to Government of Malaysia (2010), Malaysian population in terms of religion consists of 61.3 percent Muslims, 19.8 percent Buddhists, 9.2 percent Christians, 6.3 percent Hindus and 3.4 percent of its remaining population follows a diverse religious, non-religious and traditional beliefs, including Taoism, Confucianism, Atheism, and other Chinese conventional, spiritual and tribal faiths. Hence, this indicates that Malaysian society despite being a multi-cultural, multilingual and multi-religious collectively and equally respects all religions and cultures, which has resulted in a religious and cultural harmony in the country and, over the years, has become the strength for its rapidly growing economy. Another three Pakistani Ph.D. students studying in the second and fourth years, respectively, agreed altogether and commented that Malaysians celebrate and value their cultural diversity, and according to them, it is quite a positive feature of this country's culture that also helps Pakistani women to easily adjust here in Malaysia.

\section{Lifestyle}

Malaysian lifestyle was also found one the pull factors affecting Pakistani women's access to international higher education, specifically the one in Malaysia. Most of the study respondents revealed that they were very impressed with their humble nature and simple lifestyle of Malay people. They were of the view that most Pakistanis are overgenerous with a propensity to adopt a higher lifestyle than their actual social status as compared to Malaysians. Most of the respondents shared their good interactions with the local Malay people, and their love, warmth and hospitality while living side by side with them. The respondents also acknowledged the fact that Malaysians have all the necessary facilities available to maintain an affordable lifestyle, however, they remain simple and kind. A female doctoral student in the second year of her Ph.D. studies expressed: 
Malaysians are not extravagant like Pakistanis who spent so much on their food, clothes, and footwear. I have seen many locals wearing slippers in their offices, and do not care about it. In contrast, Pakistani people spend almost half of their salaries on maintaining their status and if someone does not follow this trend they start talking bad about him/her. In our country, if you have money but you do not spend it, then you are considered as a miser, whereas Malaysians save the same proportion of money because of their simple lifestyle.

Doing her Ph.D. studies on self-finance and studying in her second year, a Pakistani female student living single commented:

I like the living style of the locals here obviously because they are very simple and down to earth. If I compare them with Pakistani people, I must say that we Pakistanis are very conscious about our clothing, footwear and everything that materially relates to our social status, however, Malaysians love to live a simple and happy life.

\section{Freedom of women}

Being Pakistani Muslim women, our study respondents applauded Malaysia for giving freedom to its women. The respondents disclosed that they are very impressed to see that Malaysia is a Muslim country that offers great respect and freedom to their women. While comparing both the societies, respondents said that Pakistan should learn many things from Malaysian society, especially in terms of their lifestyle, security of women, and freedom and respect for women. According to a female doctoral student on self-finance in the fourth year of her Ph.D. studies,

You are free whatever you do. I loved to observe that both men and women offer prayers regularly. Malay women also wear Hijabs, but this does not mean that they are not intolerant and extremists, but rather they are quite liberal so far as other 
religious people and their practices matter. You can see boys and girls together with their girlfriends and boyfriends too; however, Malay society offers this freedom within the context of Islam of course. The good thing I personally experienced is that nobody interferes in the private affairs of anyone, which is very nice for Pakistani Muslim female students living over here.

A single female doctoral student studying in the second year of her Ph.D. studies affirmed:

I like Malaysia more than Pakistan because there is freedom here and you can wear whatever you want; go wherever you want, and do whatever you want. You can go outside in any dress and style, nobody bothers you. But, in Pakistan, you cannot do all these things even if maintaining the boundaries of Islam; people still interfere in your life.

The respondents also shared that the inspiration from Malaysian women has given them a new direction of hope and self-belief. According to them, their on-going experience in Malaysia will also benefit their female colleagues in Pakistan when finishing their studies and going back to different rural and urban areas of Pakistan.

\section{Security of women}

As this a case study of Pakistani Muslim women students living in Malaysia, we found that the respondents were more concerned about their security. Security has turned out to be the leading pull factors attracting Pakistani female doctoral students toward Malaysian public universities. Study results found that most of the respondents were enormously satisfied with their security and identified that equal economic opportunities for women in Malaysian society are the main reason behind their security. Figure 2 represents the verbal accounts of study respondents who described the importance of security during interviews. When asked about comparing women's 
security in Pakistan with that in Malaysia, some respondents expressed their concerns regarding insecurity, mobility restrictions, and other religious and social barriers for women in Pakistan.

The other important comparison they pointed out during the discussion was about the difference in gender roles of women between the two countries. For instance, they said that Malaysian women is work is socially more visible than Pakistani women as their work is economically visible in every sphere of life, whereas Pakistani women are mostly invisible as they are hardly seen out of the usual domestic chores. The respondents further mentioned that women are more empowered, educated and skilled in Malaysia. The respondents further said that they feel relax and free like the local Malaysian women and enjoy their life without any fear. There were also some interesting comments from one female doctoral respondent studying in the fourth year:

Malaysia should be declared as a state of women empowerment because women have been given their due social rights, specifically their socio-economic security, which we can see in terms of Malay women's freedom and empowerment all over the country.

Another Pakistani female in the second year of her Ph.D. studies on self-finance confidently shared:

My husband asked me to get admission to a Ph.D. programme of any Malaysian public university of my choice. Because I was supposed to study but live alone abroad, so I had a security concern in my mind. Thus, I decided to go to a country where I can study and survive alone without confronting any security problem. So thanks to Almighty Allah that I lastly had made the right decision about coming to Malaysia. I am not only mentally satisfied in terms of her security, but my parents are also satisfied and are not even worried that I am living alone here. 
Figure 2: The verbal accounts of study respondents on the importance of security.

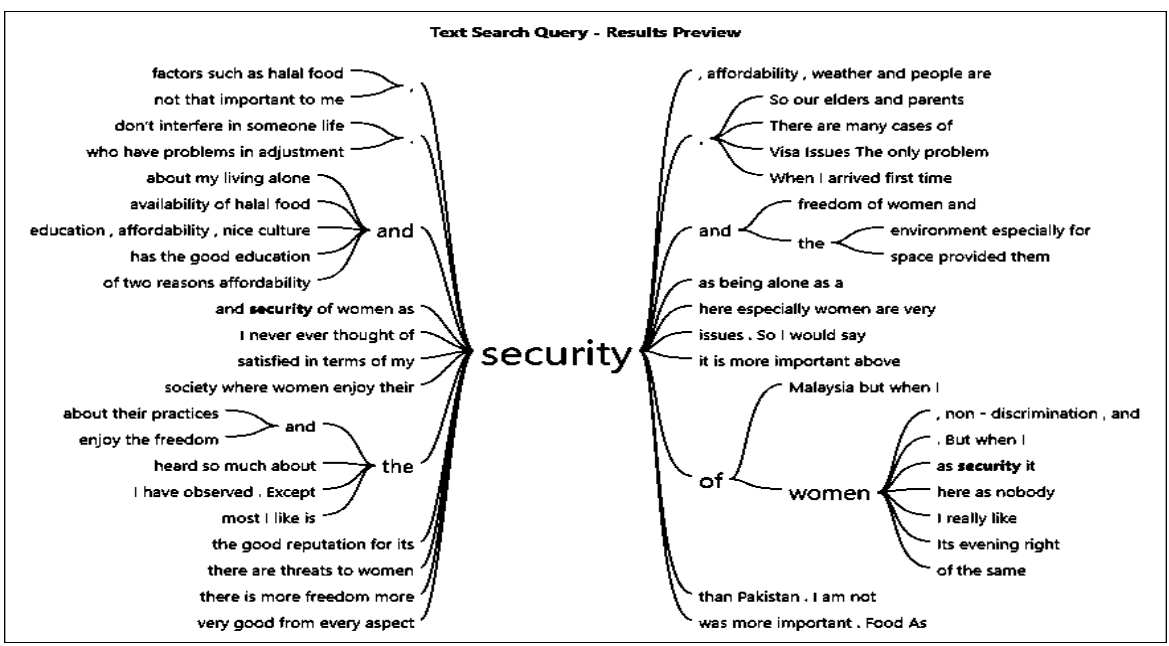

One Pakistani woman doctoral student in the fourth year under the HEC funded Ph.D. fellowship revealed that she feels more comfortable in Malaysia as she feels respected, free and independent without facing any discrimination. She further affirmed that Malaysian society has provided her woman much space to prove her economic role, make more visible her identity and give more freedom to work with the man on an equal footing in the development of their country. A Pakistani woman student in the third year of her Ph.D. studies gladly said:

When I was in Pakistan, my major concern was to go to a country where women are free and secure. Luckily, when I arrived in Malaysia I found this country very secure as I personally observed that women can roam around anywhere anytime without a fear of any security threat, except monkeys (laugh). 


\section{Findings 3: Individual Pull Factors}

\section{Previous international experience}

There were few respondents among the study sample who had been international higher education experience before and previously studied in well-developed countries, such as the USA, Canada, the UK, Germany, France, and Australia. During interviews, we enquired about their previous study experiences in those countries and their comparison with higher education in Malaysia. Interestingly, none of them had talked about their academic and research experiences, but most of them explained the improvement in the higher education systems in both countries, including Malaysia and Pakistan.

Although one of the respondents exceptionally mentioned that the USA was safer than Malaysia in terms of security of women, however, the rest of the study respondents praised the security of women in Malaysia. Studying in the fourth year of her doctoral studies, a female doctoral student with the HEC Ph.D. fellowship commented:

I was initially enrolled in MS leading to a PhD programme and successfully did my MS from Denmark; however, I encountered some personal problems and finally could not complete my Ph.D. degree. In Denmark, both students and teachers enjoy too much freedom. Although the environment was also relaxed and both students and teachers mutually decide about the compulsory courses, but there were no hard and fast rules regarding student's attendance or dress code restriction.

A female respondent in the fourth year of her Ph.D. studies had been to the USA for her MS. In her opinion, America has a much better education system, things are smooth and your fellows are friendlier and cooperative. Although there is an issue of Halal food upon your arrival, that too was not distressing as one could find Halal food once getting familiar with its availability in the nearby markets. When asked about comparing Malaysia with America, she considered the 
later much safer. One of the married female doctoral students in the fourth year explained:

I was not planning to do a Ph.D. from Pakistan as I did my Masters from Australia, so I personally considered that doing a PhD. from Pakistan may not be according to international higher education standards. During my stay in Australia, I met some Malaysian Muslim female students over there, who told me how expensive Australia is as compared to Malaysia. Except for the security of women, I am not impressed with both the freedom and weather in Australia. Sometimes I think that had I not been in Australia I would have enjoyed more here in Malaysia.

\section{Higher education of Malaysia and Pakistan}

One of the most important pull factors we identified during our discussions was respondents' comparison pertaining to Malaysian and Pakistani higher education. This factor was found principally the main reason for almost all the respondents before coming here for their higher studies. Most of the respondents were of the view that Malaysia has comparatively better higher education facilities than the same in Pakistan. On the contrary, some of the respondents were not glad after entering Malaysian public universities and expressed that some Pakistani universities were also better for pursuing higher education. When thoroughly investigated, few respondents unanimously disclosed that Malaysian public universities offer fast track doctoral degrees as compared to Pakistani institutions which take more than five years to complete a Ph.D. degree. They further differentiated that Malaysian the academicians (or supervisors) are better in research, whereas Pakistani supervisors are relatively better in teaching. There was also an interesting comment made by a married female doctoral student studying in the fourth year of her Ph.D. studies: 
In Pakistan, the supervisors satisfy students in Pakistan, whereas it is the other way round in Malaysia where students satisfy their supervisors.

While comparing higher education in Pakistan with that in Malaysia, another female doctoral student studying in her second year and working as a researcher in both countries under the split-doctoral fellowship programme funded the HEC, Pakistan, commented:

In Malaysia, the supervisors are not guiding as they should and they are not providing the quality time to their students, however, the supervisors in Pakistan give quality time to students until the students are satisfied. Due to this specific difference between the higher education system of both countries, the supervisors in Malaysian public universities expect their students to work on their own without relying more on them. However, supervisors in Pakistan help their students whenever they face any dilemma during their Ph.D. research process.

\section{Family bond}

One of the factors which many of the married respondents shared was to come with their families. The respondents said that Malaysia was the only place where they can afford to live with their families, so this obviously implies that the majority of the married respondents were being pulled by their wives who were already studying here in Malaysia for the purpose of getting a doctoral degree. Out of 13 married female students, only one was living without her children and/or husbands. Likewise, but somewhat unique as compared to the above context, one of the respondents was being compelled by her sister who was already studying in Malaysia.

According to a single female doctoral student on self-finance, her sister was doing a Ph.D. in the field of economics from a university located in the Western Malaysia, who always used to motivate her to 
come here and do Ph.D. She further described that she was never interested; however, when she travelled to Malaysia to meet her, her sister successfully convinced her to stay and process her Ph.D. admission.

\section{Conclusions}

Based on an open-ended qualitative research approach of data collection, originally developed from Grounded Theory (GT) methodology, and constant comparative analysis of responses collected through the semi-structured interviews, this study with its main purpose of investigating and analysing the push and pull factors involved in motivating Pakistani female doctoral students to pursue quality international higher education identified affordability as a predominant push factor besides other related push factors, including scholarship condition imposed by the HEC, Pakistan, to choose Malaysia as country of destination because of its affordable tuition fees and living expenses in the Malaysian public universities. Furthermore, cultural diversity and lifestyle were identified and analysed as the general pull factors overall affecting Pakistani women's access to their international higher education, whereas previous international experience, personal comparison made between Pakistani and Malaysian higher education, the security of women, freedom for women and family bond were identified as the individual pull-factors.

Our study, therefore, concludes that the education affordability (i.e. affordable tuition fees and living expenses) remains the main push factors in addition to the principal pull factor that makes Malaysia as a preferred Islamic state and eventually a country of a destination for Pakistani women students pursuing their Ph.D. studies in the different Malaysian public universities. Among others, cultural diversity, lifestyle, security of women, freedom for women were found as the general pull factors overall affecting Pakistani women's access to their international higher studies, whereas students' 
previous international experience, the personal comparison made between Pakistani and Malaysian higher education and family bond were identified as the individual pull factors affecting Pakistani female students more directly.

The detailed study review offers some lessons learned for the betterment of our higher education system in Pakistan in the future. Realising the fact that the security situation in Pakistan has largely improved during the last decade, knowing that Pakistani public universities are relatively more affordable both in terms of tuition fees and living expenses, particularly across South Asia, Middle East, and even South-East Asia, and considering the advantages of being an Islamic state like Malaysia, having a diverse national culture across our four provinces, and increasing evidences pertaining to an access to fair justice from the present judicial system, our public universities have a broader prospects for internationalising their higher education programmes in these countries. However, the above goal can be only accomplished if the quality of our higher education gets improved through adequate funding for our public universities in parallel with both the merit-based administrative and teaching appointments. If the above policy parameters are appropriately implemented, we can also make Pakistan as a country of international higher education destination for Muslim women doctoral students coming from abroad.

\section{References}

Andrade, M. S. (2006). International students in English-speaking universities adjustment factors. Journal of Research in International Education, 5(2), 131-154.

Altbach, P. G. (2004). Globalisation and the university: Myths and realities in an unequal world. Tertiary Education and Management, 10(1), 3-25.

Altbach, P. G., and Knight, J. (2007). The internationalization of higher education: Motivations and realities. Journal of Studies in International Education, 11(3-4), 290-305. 
Batool, S. Q., Sajid, M., and Shaheen, I. (2013). Gender and higher education in Pakistan. International Journal of Gender \& Women Studies , 1(1), 15 -28 .

Bohm, A., Follari, M., Hewett, A., Jones, S., Kemp, N., Meares, D., and Van Cauter, K. (2004). Forecasting international student mobility: A UK perspective. London: British Council.

Briers, G. E., Shinn, G. C., and Nguyen, A. N. (2010). Through students' eyes: Perceptions and aspirations of a college of agriculture and life science students regarding international educational experiences. Journal of International Agricultural and Extension Education, 17(2), 520.

Chan, S. J. (2012). Shifting patterns of student mobility in Asia. Higher Education Policy, 25(2), 207-224.

Creswell, J. W. (2014). Research Design: Qualitative, Quantitative, and Mixed Methods Approach (4th ed.). California: Sage Publications, Inc.

Syed, F. H. , Talpur, M. A., and Shaikh, I. (2018). Factors influencing Muslim international students to Malaysian public universities: A case study of Pakistani female doctoral students. Asia Pacific, 36, 127 - 144.

Glaser, B., \& Strauss, A. (1967). The discovery grounded theory: Strategies for qualitative inquiry. London: Weidenfeld and Nicolson.

Glaser, B. G. (1992). Emergence vs Forcing: Basics of Grounded Theory Analysis. Mill Valley: Sociology Press.

Glaser, B. G. (1998). Doing Grounded Theory: Issues and discussions. California: Sociology Press.

Government of Pakistan (2018). Pakistan Economic Survey (2018-19), Chapter 10: Education. Islamabad: Ministry of Finance.

Government of Malaysia (2010). Population Distribution and Basic Demographic Characteristics. Kaulalampur: Department of Statistics, Federal Government Administrative Centre,

Haider, S. Z. (2008). Challenges in higher education: Special reference to Pakistan and South Asian developing countries. Nonpartisan Education Review/Essays, 4 (2), 1 - 10. 
Li, M., and Bray, M. (2007). Cross-border flows of students for higher education: Push-pull factors and motivations of mainland Chinese students in Hong Kong and Macau. Higher Education, 53(6), 791-818.

Kazmi, S. W. (2005). Role of education in globalization: A case for Pakistan. SAARC Journal of Human Resource Development, 1, 90-107.

Khalid, H. S., and Mujahid-Mukhtar, E. (2002). The Future of Girls' Education in Pakistan: A Study on Policy Measures and other Factors determining Girls' Education. Islamabad, UNESCO Office, Pakistan.

Knight, J. (2006). Internationalization of higher education: New directions, new challenges. The 2005 IAU global survey report, Paris: International Association of Universities.

Koehne, N. (2005). (Re)construction: Ways international students talk about their identity. Australian Journal of Education, 49(1), 104-119.

Malik, S., and Courtney, K. (2011). Higher education and women's empowerment in Pakistan. Gender and Education, 23(1), 29-45.

Mazzarol, T., and Soutar, G. N. (2001). The Global Market for Higher Education: Sustainable Competitive Strategies for the New Millennium. Cheltenham: Edward Elgar.

Murtaza, K. F. (2012). Women empowerment through higher education in Gilgit-Baltistan. International Journal of Academic Research in Business and Social Sciences, 2 (9), 343-367.

NVIVO (2018). Nvivo-11 Pro Software, QSR International (Pvt) Limitd., US / UK / Australia.

OECD (2013). Education Indicators in Focus 2013/05 (July), Paris: Organization for Economic Cooperation \& Development (OECD).

Oleksiyenko, A., Cheng, K.M., and Yip, H.-K. (2013). International student mobility in Hong Kong: private good, public good, or trade-in services? Studies in Higher Education, 38(7), 1079-1101.

Sherry, M., Thomas, P., and Chui, W. H. (2010). International students: A vulnerable student population. Higher Education, 60(1), 33-46. 
Sirat, M. (2008). The impact of September 11 on international students flow into Malaysia: Lessons learned. IJAPS, 4(1), 80-95.

Strauss, A., and Corbin, J. (1998). Basics of Qualitative Research: Techniques and Procedures for Developing Grounded Theory (2nd Edn.). California: SAGE Publications, Inc.

Strauss, A., and Corbin, J. M. (1990). Basics of Qualitative Research: Grounded Theory, Procedures, and Techniques,.USA: Sage Publications, Inc. 